\title{
Lack of Promoting Linkages Between Scientific Creativity and The Arts
}

\author{
Johannes Lehmann ${ }^{1 *}$ and Bill Gaskins ${ }^{2}$ \\ ${ }^{1}$ Atkinson Center for a Sustainable Future, Cornell University, USA \\ ${ }^{2}$ Department of Art, Cornell University, USA
}

*Corresponding author: Johannes Lehmann, Atkinson Center for a Sustainable

Received Date: March 11, 2019

Future, Cornell University, USA.

\section{Short Communication}

The United Nations World Creativity and Innovation Day was for the first time celebrated globally in 2018 (UN Resolution A/ RES/71/284). It culminated the World Creativity and Innovation Week in April 2018 (https://www.wciw.org/) that started with Leonardo da Vinci's birthday. Even though creativity has been implicitly highly valued in the sciences, is common in industry, and has been associated with multi-disciplinary talents such as da Vinci, it is not institutionally promoted in the natural sciences to any relevant extent. The UN delegates called for harnessing creativity to address sustainability issues, but the sciences are sorely absent from this discourse. We argue that close observation of artistic creativity will provide essential and urgently needed advice on scientific progress. Important lessons about educating for [1] and promoting creativity in the sciences [2] can be learned from advances in understanding of the creative process in the arts.

Science policy at the institutional level will need to radically shift towards an incentive structure that rewards creativity in the sciences through a long-term educational vision that truly integrates arts and sciences [3] rather than short-term cross-disciplinary training. Acknowledging creativity as central to scientific pursuit, actively utilizing chance and failure in scientific experimentation, and allowing mental space to reflect on scientific results or plans, are all critical for step changes in scientific knowledge. Such an iterative and open-ended processes of scientific inquiry should be modeled after insights from art practices.
Radical collaborations across arts and science on an equal playing field are especially relevant for sustainability research and will require new policy instruments within institutions of higher learning as well as between universities and industry. Increasingly complex societal and policy solutions to future sustainability challenges must be based on an ever-broader understanding of science advances, since ideological, corporate and political circumstances challenge unambiguous assessment of the creativity of the scientific product. Examining scientific creativity through the lens of artistic practice will allow identification of a path towards an institutional environment that explicitly values and promotes creativity for the sciences.

\section{Acknowledgement}

None.

\section{Conflict of Interest}

No conflict of interest.

\section{References}

1. Scheffer, MM Baas, TK Bjordam (2017) Teaching originality? Common habits behind creative production in science and arts. Ecology and Society 22(2): 29 .

2. Bohm B (1968) On creativity. Leonardo 1(2): 137-149.

3. Gurnon D, Voss-Andreae J, Stanley J (2013) Integrating art and science in undergraduate education. PLoS Biology 11(2): e1001491. 